\title{
Good Survival after Reirradiation
}

National Cancer Institute

\section{Source}

National Cancer Institute. Good Survival after Reirradiation. NCI Thesaurus. Code C127865.

A score of 1 on the Combs Prognostic Index scale. 